\title{
Morphology and Contractility of Cardiac Myocytes in Early Stages of Streptozotocin-Induced Diabetes Mellitus in Rats
}

\author{
M. CAGALINEC ${ }^{1,2,4}$, I. WACZULÍKOVÁ ${ }^{1}$, O. ULIČNÁ ${ }^{3}$, D. CHORVAT JR. ${ }^{2}$
}

${ }^{1}$ Department of Nuclear Physics and Biophysics, Division of Biomedical Physics, Faculty of Mathematics, Physics and Informatics, Comenius University, Bratislava, Slovakia, ${ }^{2}$ International Laser Centre, Bratislava, Slovakia, ${ }^{3}$ Pharmacobiochemical Laboratory, Third Department of Internal Medicine, Faculty of Medicine, Comenius University, Bratislava, Slovakia, ${ }^{4}$ Department of Pharmacology, Medical Faculty, University of Tartu, Tartu, Estonia

Received September 14, 2012

Accepted June 7, 2013

On-line September 10, 2013

\section{Summary}

Diabetic cardiomyopathy is the leading cause of mortality in type 1 diabetes. Thus study of cardiomyocyte morphology and function during early stages of diabetes using modern analytical methods is of critical importance. Therefore, using confocal microscopy, we determined metric parameters, volumes and contractility, with calcium transients in isolated left-ventricular myocytes at one week after induction of diabetes in rats. Myocyte volume analysis from 3D confocal scans was performed using an automated contour detection algorithm that took the actual shape of the myocytes into account. We showed a significant reduction in myocyte volume in diabetic animals. We also showed a significant reduction in length and width but not in thickness of the myocytes, which suggests disproportional reorganization of the structure of the heart tissue during short-term diabetes. From a functional point of view, we observed a significant decrease in cell shortening at a stimulation frequency of $0.5 \mathrm{~Hz}$. This was accompanied by a decrease in calcium transient amplitude. Together, these data suggest that impaired calcium handling is one of the factors that contributes to the observed decrease in myocyte shortening during early stages of streptozotocin-induced diabetes in rats.

\section{Key words}

Diabetes mellitus - Left ventricular myocyte - Myocyte volume • Contractility $\bullet$ Calcium transient

\section{Corresponding author}

M. Cagalinec, Department of Pharmacology, Faculty of Medicine, University of Tartu, Ravila 19, 51014 Tartu, Estonia. E-mail: michal.cagalinec@ut.ee

\section{Introduction}

Complications in cardiac function are a leading cause of morbidity and mortality in type 1 diabetic patients (Danaei et al. 2011). Diabetes-induced cardiac dysfunction, or diabetic cardiomyopathy, develops independently of vascular disease (Bertoni et al. 2003). Diabetic cardiomyopathy is characterized by alterations in ventricular muscle morphology and a decrease in myocardial performance, both of which occur during the final stages of cardiomyopathy and lead to ventricular contractile dysfunction. As cardiac myocytes are responsible for ventricular contractile function, a detailed analysis of the morphology and contractile abnormalities in myocytes during early stages of diabetes is critical.

Electron microscopy has shown that the morphological remodelling of cardiac myocytes during diabetes involves loss and atrophy of cardiac myocytes (Giacomelli and Wiener 1979). Reduction in myocyte contacts has been noted in diabetic rats, indicating a negative rearrangement of diabetic cardiac tissue (Dyntar et al. 2006). In contrast, results specifically regarding morphometry of ventricular myocytes in diabetes are contradictory: upon histological examination of left ventricular walls, diameters of myocytes are either unchanged (Kita et al. 1991, Stilli et al. 2007) or reduced (Nemoto et al. 2006). Moreover, available data on myocyte volume under diabetic conditions are either calculated using histomorphometric techniques (Fiordaliso et al. 2006) or simple geometric 
approximations, thus neglecting the complexity of cardiac myocyte shape (Stilli et al. 2007).

Contractile abnormalities of individual myocytes in experimental diabetes include reduced myocyte contractility and relaxation confirmed by a reduction in calcium transients (Ding et al. 2006, Wickley et al. 2006). Several authors have shown reduced $\mathrm{Ca}^{2+}$ entry through the voltage dependent $\mathrm{Ca}^{2+}$-channel in cardiac myocytes isolated from rats with streptozotocin (STZ)induced diabetes mellitus (Wang et al. 1995, Chattou et al. 1999, Bracken et al. 2004). Moreover, myocyte contractility is affected by alterations in contractile proteins themselves, as described during the fourth to eighth week after induction of experimental diabetes in rats (Malhotra and Sanghi 1997).

However, little is known of the morphological and contractility changes that occur in cardiac myocytes during the early stages of diabetes (Chattou et al. 1999). A majority of the studies describe later stages, generally between the eighth and twelfth week after induction of diabetes (Malhotra and Sanghi 1997, Bracken et al. 2004, Wickley et al. 2006). Moreover, experimental data combining morphological and contractile alterations of diabetic cardiac myocytes isolated from the same experimental animal are largely absent. Therefore, the aim of this study was to use confocal microscopy followed by advanced image processing techniques to determine metric parameters and volume together with shortening and calcium transients in myocytes isolated from rats at seven days after streptozotocin-induced diabetes.

\section{Materials and Methods}

\section{Chemicals}

All chemicals were of analytical grade and, if not otherwise specified, purchased from Sigma-Aldrich USA, SERVA or Merck.

\section{Animals}

Eighteen male, adult, albino Wistar rats weighing between 300 and $350 \mathrm{~g}$ were used. Rats were housed under a standard 12:12 h light/dark regimen at a temperature of $22 \pm 2{ }^{\circ} \mathrm{C}$. A standard balanced pellet diet and tap water were provided ad libitum. Robust (pseudo)random number generation was used to allocate the animals to two independent groups: $n=8$ for control and $\mathrm{n}=10$ for diabetes. All experiments were performed in compliance with the guidelines for the care and use of experimental animals and approved by the State Veterinary and Alimentary Administration of the Slovak Republic No. 2824/07-221.

\section{Induction of experimental diabetes}

Diabetes was induced by a single dose of streptozotocin (65 mg. $\mathrm{kg}^{-1}$ b.wt.) dissolved in $0.1 \mathrm{~mol} . \mathrm{l}^{-1}$ citrate buffer, $\mathrm{pH} 4.5$, injected into the tail vein. The control animals were not treated with streptozotocin and received an equal volume of the above-mentioned citrate buffer in parallel (Howarth et al. 2002). The development of diabetes in the rats was confirmed when blood glucose (glucostrips, Blood Glucose Sensor Electrodes, MediSense, Abbot Laboratories, Bedford, UK) was above $15 \mathrm{mmol}^{-1}$.

\section{Biochemical analysis}

At seven days after streptozotocin administration, the rats were anesthetized with thiopental $\left(45 \mathrm{mg} \cdot \mathrm{kg}^{-1}\right)$. Blood from the abdominal aorta was collected in heparinized tubes. The plasma concentrations of glucose, albumin, creatinine, total proteins, total cholesterol, triacylglycerols, uric acid, urea and the activities of alanine transaminase (ALT) and aspartate transaminase (AST) were determined using an Hitachi Analyzer Model 911 and the appropriate kits from Roche Company (Switzerland).

\section{Isolation of left ventricular cardiac myocytes}

After blood collection and bilateral thoracotomy, the left ventricular myocytes were isolated as published by Zahradník and Palade (1993). The heart was cannulated and perfused retrogradely via the aorta using modified Tyrode's solution (composition below) supplemented with $0.75 \mathrm{mmol}^{-1} \mathrm{CaCl}_{2}$, then with calcium-free Tyrode's solution $\left(0.1 \mathrm{mmol}^{-1} \mathrm{l}^{-1}\right.$ EGTA) and finally with Tyrode's solution containing $1 \mathrm{mg} \cdot \mathrm{ml}^{-1}$ collagenase (type II, Gibco BRL) and $0.01 \mathrm{mg} . \mathrm{l}^{-1}$ protease (type XIV, Sigma-Aldrich) in low $\mathrm{CaCl}_{2}\left(50 \mu \mathrm{mol} .1^{-1}\right)$ at $36{ }^{\circ} \mathrm{C}$. All solutions were oxygenated using $95 \% \mathrm{O}_{2} /$ $5 \% \mathrm{CO}_{2}$. The batches of myocytes were resuspended in enzyme-free Tyrode's solution containing $0.75 \mathrm{mmol}^{-\mathrm{l}^{-1}}$ $\mathrm{CaCl}_{2}$. After isolation, the myocytes were stored at $4{ }^{\circ} \mathrm{C}$ until analysis to prevent deprivation of energy levels. Only rod-shaped cells with clearly defined sarcomere striations and without blebs were analyzed at up to $10 \mathrm{~h}$ after isolation.

The modified Tyrode's solution contained (in mmol. $\left.1^{-1}\right): \quad \mathrm{NaCl} 130.0 ; \quad \mathrm{KCl} 5.4 ; \quad \mathrm{MgCl}_{2} \cdot 6 \mathrm{H}_{2} \mathrm{O}$ 1.4; 
$\mathrm{NaH}_{2} \mathrm{PO}_{4}$ 0.4; creatine 10.0; taurine 10.0; glucose 10.0; and 4-(2-hydroxyethyl)-1-piperazineethenesulfonic acid (HEPES) 10.0; it was titrated to $\mathrm{pH} 7.3$ using 1 mol.1 ${ }^{-1}$ $\mathrm{NaOH}$. During the experiment, myocytes were perfused with Tyrode's solution containing $1.2 \mathrm{mmol}^{-1} \mathrm{CaCl}_{2}$. Collagenase was purchased from Gibco BRL; $\mathrm{NaCl}$, $\mathrm{MgCl}_{2}, \mathrm{NaH}_{2} \mathrm{PO}_{4}$, thiopental and heparin were from Lachema (Czech Republic).

Volume, calcium transients and cell-shortening determination

For myocyte volume rendering, myocytes were stained with the acetoxymethyl (AM) form of Calcein $\left(0.1 \mu \mathrm{mol} . \mathrm{l}^{-1}\right.$ for $10 \mathrm{~min}$, room temperature $)$. For recording of calcium transients, myocytes were loaded with the calcium indicator Fluo-3/AM ( $1 \mu \mathrm{mol} .1^{-1}$ for $10 \mathrm{~min}$ at room temperature). Cells were then centrifuged at $50 \mathrm{~g}$ for $1 \mathrm{~min}$, resuspended in the Tyrode's solution containing $1.2 \mathrm{mmol}^{-1} \mathrm{CaCl}_{2}$ and incubated for $20 \mathrm{~min}$ to ensure complete intracellular hydrolysis of the fluorescent dye esters. Cells were allowed to settle onto a coverslip with perfusion (rate $1 \mathrm{ml} . \mathrm{min}^{-1}$ ). Fluorescence was collected with a filter set 09 (ex/em 480/515 nm) following excitation by an Ar:ion laser line at $488 \mathrm{~nm}$ (Lasos Lasertechnik) using a confocal microscope LSM 510 (Zeiss) equipped with a water immersion objective (40×, NA 1.2).

Three-dimensional stacks of Calcein-stained cardiomyocytes were obtained by successive scanning of $2 \mathrm{D}$ confocal optical planes using non-cubic voxels at 2-micron step sizes in the z-axis using a pinhole opening of 1 Airy unit corresponding to optical slices of $0.9 \mu \mathrm{m}$. Only mono- or binucleated myocytes (nuclei detected as areas of low Calcein fluorescence inside the cell showing typical shape and localisation, no additional staining applied) were taken for imaging. Cell volume was estimated from the $3 \mathrm{D}$ confocal stacks using an automatic cell-border-detection method (Fig. 2A) introduced by Dr. Anton Mateašík (published recently in Chorvatova et al. 2012) based on an active contour algorithm (Kass et al. 1987). This method was applied for every 2D slice to calculate the area occupied by the cell investigated. Cell volume was then defined as the sum of these areas multiplied by the optical slice thickness. The length of the myocyte was defined as the maximum distance between the borders of the Calcein-stained cell in the x-axis. The width and thickness of the cell were analysed using the $y$ - and z-axes from the orthoslice projection (Fig. 1A) as the maximum distance between the cell borders in the $y$ - and z-axes, respectively. From these two measurements, the longer was considered the width and the shorter the thickness. The volume was then calculated as an elliptic cylinder (a geometrical approximation) as follows: (length $\times$ width $\times$ thickness $\times \pi$ ) $/ 4$.

For cell calcium transients and cell shortening, Fluo-3-labeled cells were perfused at a rate of $1 \mathrm{ml} . \mathrm{min}^{-1}$ and paced to contract at a frequency of 0.5 or $2.0 \mathrm{~Hz}$ using field stimulation ( $4 \mathrm{~ms}, 5 \mathrm{~V} . \mathrm{cm}^{-1}$ corresponding to $10 \%$ above the threshold level to induce contraction) via platinum electrodes. All recordings were performed at room temperature. A rapid line scan confocal imaging protocol $(5 \mathrm{~ms})$ was used to record contractions and calcium transients quasi-simultaneously (both the transmission and fluorescence channel acquired up to $1 \mathrm{~ms}$ ). At least eight consecutive contractions were taken for calcium transient amplitude (CTA) and cell shortening analyses. From the fluorescence line scan (Fig. 4A, right panels), the intracellular signal was averaged along the $\mathrm{x}$-axis per stimulation point. Peak fluorescence intensity was taken as the maximum of the averaged fluorescence intensity profile, resting fluorescence was set as the final value before the intensity started to rise due to calcium release (Fig. 4B). The calcium transient amplitude (CTA) was defined as the ratio of peak (systolic) and resting (diastolic) Fluo-3 fluorescence intensity. In the brightfield line scans (Fig. 4A, left panels), the cell borders were analyzed by software developed by Dr. Jaroslav Placek that provided an automatic border detection based on simple intensity thresholding and on automatic calculation of the distance between the two borders. At least eight consecutive contractions were then averaged (y-axis in Fig. 4A). Maximal cell shortening was set as the minimum length, the resting cell length was taken as a value in the middle between stimulation points. Cell shortening was defined as the ratio of maximum cell shortening to resting cell length and was expressed as a percentage.

\section{Statistical analysis}

For length, width and thickness, 76 cells in total were analyzed from the control group and 86 cells from the diabetic group. Rendered volumes $\left(\mathrm{V}_{\mathrm{r}}\right)$ and elliptical cylinder approximation volumes $\left(\mathrm{V}_{\mathrm{e}}\right)$ were estimated from the same myocyte to enable calculation of the $\mathrm{V}_{\mathrm{r}} / \mathrm{V}_{\mathrm{e}}$ ratio, and were determined from 70 cells in the control group and from 75 cells in the diabetic group. For cell shortening, 70 cells were analyzed from the control group and 82 from the diabetic group. In a subset of these cells 
(27 controls and 29 diabetic), the CTA was assessed. The latter was then used for a further correlation analysis between CTA and cell shortening.

Normally distributed data (according to the Shapiro-Wilk's test) are presented as the mean $\pm \mathrm{SD}$; for skewed data, the median and interquartile range [IQR: from lower (25\%) quartile (LQ) to upper (75\%) quartile (UQ)] were used. Coefficients of variation, which do not rely upon unit scales, were used to describe the dispersion between metric variables. Analysis of variance was used to assess and compare intra-individual versus interindividual variability for metric parameters.

To test for the effects between groups and between subgroups within groups, we used analysis of variance (ANOVA) to uncover hierarchical random effects. Unpaired, two-tailed t-tests were performed if only two groups were analyzed. For raw data showing departures from normality, non-parametric alternative Mann-Whitney U tests were used. The respective $95 \%$ confidence limits (CLs) for the difference between medians or means are reported.

The strength of a linear association between two variables was evaluated using Pearson's product moment correlation coefficient r. For skewed data, a distribution free test of independence was performed and Kendall's rank correlation coefficient was used.

All data in figures except the correlation analysis are presented as means (for length, width, thickness, volume-geometric approximation, ratio rendered/ approximation) or medians (for rendered volume) for animals, thus data presented in Figure 1, Figure 2 and Figure $3 \mathrm{~A}$ and $\mathrm{C}$ are means/medians from eight and ten animals.

All data were analyzed at the $5 \%$ level of significance using StatsDirect ${ }^{\circledR}$ 2.6.6 (StatsDirect Ltd., Cheshire, UK). Graphs of the data were made using Excel 2003 (Microsoft Co.).

\section{Results}

\section{Body weight and selected biochemical parameters}

The induction of diabetes mellitus was confirmed by the significantly increased plasma glucose concentration of $27.0 \pm 3.1 \mathrm{mmol}^{-1}$ in the diabetic group compared with $6.9 \pm 0.6$ mmol. $\mathrm{l}^{-1}$ in the controls when measured at $24 \mathrm{~h}$ after streptozotocin injection. The glucose level in the diabetic group estimated at the seventh day was not changed when compared to values from day one after induction of diabetes $\left(30.3 \pm 1.5 \mathrm{mmol}^{-1} \mathrm{l}^{-1}\right.$. The mean weight of the animals before induction of diabetes was $319 \pm 12$ g. The weight of diabetic animals on day seven was $286 \pm 10 \mathrm{~g}$, which was significantly lower than in the control group $(339 \pm 18 \mathrm{~g}, \mathrm{p}<0.001$, unpaired Student's t-test). Moreover, on the seventh day after the streptozotocin injection, the weight of the diabetic animals was significantly lower when compared with their weight before induction of diabetes $(p<0.001$, paired Student's $\mathrm{t}$-test). The concentration of creatinine was significantly higher in the diabetic rats than the respective values in the control group. The level of total cholesterol was increased in the diabetic group with a borderline probability value $(p=0.06)$. All estimated biochemical parameters are summarized in Table 1.

Table 1. Body weight, glucose level and selected biochemical parameters in plasma of the STZ-injected and control animals.

\begin{tabular}{|c|c|c|c|}
\hline & $\begin{array}{c}\text { Control } \\
(n=8)\end{array}$ & $\begin{array}{c}\text { Diabetic } \\
(n=10)\end{array}$ & $\mathbf{p}$ \\
\hline $\begin{array}{l}\text { Body weight } \\
\text { (g) }\end{array}$ & $334.4 \pm 20.6$ & $285.5 \pm 10.4$ & $<0.05$ \\
\hline $\begin{array}{l}\text { Glucose } \\
\left(\text { mmol. }^{-1}\right)\end{array}$ & $6.9 \pm 0.2$ & $27.0 \pm 3.1$ & $<0.001$ \\
\hline $\begin{array}{l}\text { Total proteins } \\
\left(g . l^{-1}\right)\end{array}$ & $43.1 . \pm 1.3$ & $44.3 \pm 1.3$ & ns \\
\hline $\begin{array}{l}\text { Albumin } \\
\left(g . l^{-1}\right)\end{array}$ & $19.5 \pm 0.4$ & $19.3 \pm 0.5$ & ns \\
\hline $\begin{array}{l}\text { Creatinine } \\
\left(\mu \mathrm{mol} . l^{-1}\right)\end{array}$ & $36.0 \pm 2.4$ & $56.4 \pm 4.2$ & $<0.01$ \\
\hline $\begin{array}{l}\text { ALT } \\
\left(\mu k a t . l^{-1}\right)\end{array}$ & $0.6 \pm 0.1$ & $0.9 \pm 0.1$ & ns \\
\hline $\begin{array}{l}A S T \\
\left(\mu k a t . l^{-1}\right)\end{array}$ & $1.0 \pm 0.1$ & $1.0 \pm 0.1$ & ns \\
\hline $\begin{array}{l}\text { Total cholesterol } \\
\left(\text { mmol. }^{-1}\right)\end{array}$ & $0.98 \pm 0.06$ & $1.11 \pm 0.04$ & 0.06 \\
\hline $\begin{array}{l}\text { Triacylglycerols } \\
\left(\text { mmol. }^{-1}\right)\end{array}$ & $0.8 \pm 0.2$ & $1.0 \pm 0.2$ & ns \\
\hline $\begin{array}{l}\text { Uric acid } \\
\left(\mu \mathrm{mol} . l^{-1}\right)\end{array}$ & $78.8 \pm 5.2$ & $60.8 \pm 11.2$ & ns \\
\hline $\begin{array}{l}\text { Urea } \\
\left(\text { mmol. } l^{-1}\right)\end{array}$ & $6.9 \pm 0.5$ & $9.4 \pm 1.0$ & ns \\
\hline
\end{tabular}

\section{Left ventricular myocyte morphology}

The metric parameters - length, width and thickness - were measured from acquired 3D confocal scans (Fig. 1A). We observed a significant decrease 
$(p<0.001)$ in the length of the diabetic myocytes (113.9 $\pm 7.3 \mu \mathrm{m}, \mathrm{N}=86$ cells analyzed) compared with the controls $(128.9 \pm 5.6 \mu \mathrm{m}, \mathrm{N}=76)$. The $95 \% \mathrm{CLs}$ for the difference between the means was 7.9-21.9 $\mu \mathrm{m}$. The width of the diabetic myocytes was also decreased $33.1 \pm 4.6 \mu \mathrm{m} \quad(\mathrm{N}=86) \quad$ versus $39.1 \pm 3.0 \mu \mathrm{m} \quad$ (control; $\mathrm{N}=76$ ); lower and upper CLs were 1.7 and $10.3 \mu \mathrm{m}$ $(p=0.009)$, respectively. The thickness of the myocytes was not significantly changed; the mean thickness of diabetic cells was $23.5 \pm 2.5 \mu \mathrm{m} \quad(\mathrm{N}=86)$ and was $24.7 \pm 3.6 \mu \mathrm{m}(\mathrm{N}=76)$ in the control cells; $95 \%$ CLs were 1.9 and $4.3 \mu \mathrm{m}$ (Fig. 1B), respectively. Inter-individual variability (between animal heterogeneity) in the set of metric parameters (length, width and thickness), as assessed using two-way ANOVAs, was higher among the animals of the control group $(p=0.025)$ than the diabetic group $(\mathrm{p}=0.53)$.
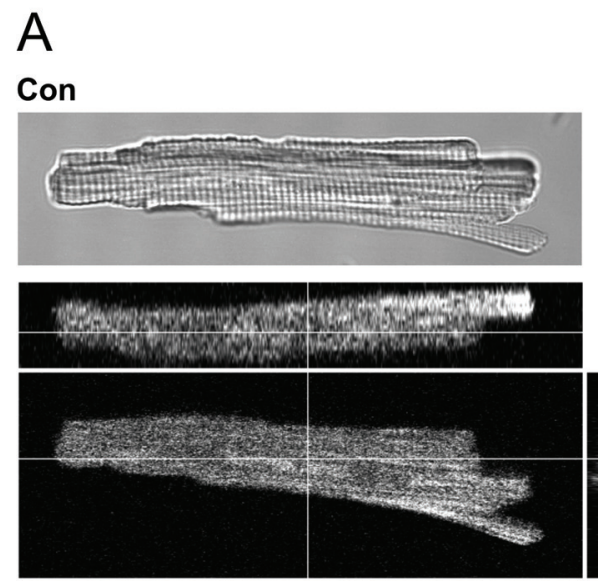

\section{Dia}
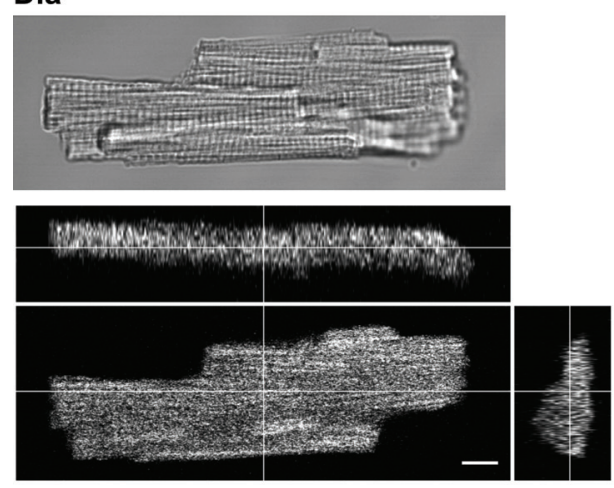

B
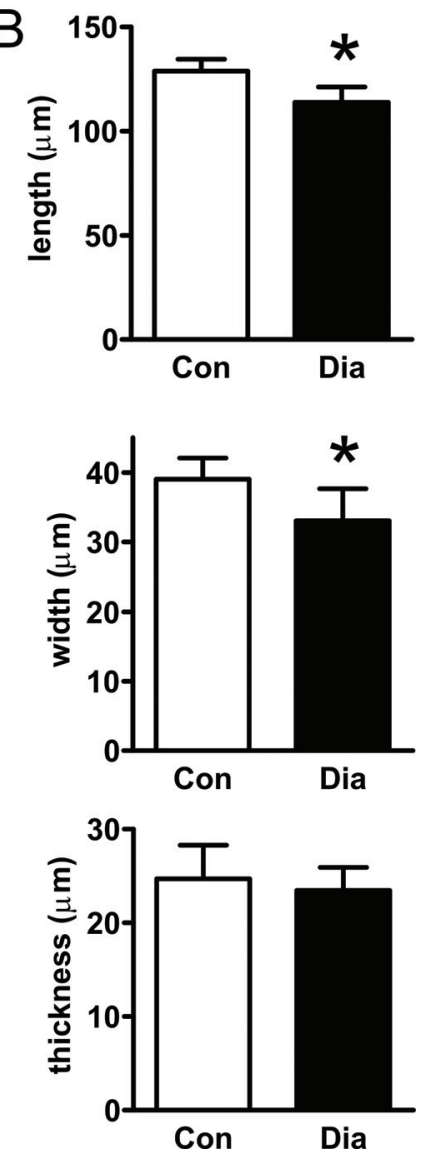

Fig. 1. Metric parameters of the left ventricular myocytes. A) A brightfield image and a 3D confocal stack shown as an orthoslice projection. Length, width and thickness were taken as the maximal distance of the myocyte in the $x-, y$ - and z-axes. Bar: $10 \mu \mathrm{m}$ for all images. B) Bar charts of the myocyte length, width and thickness. Con - control group, Dia - diabetic group. Data are presented as the mean \pm SD.

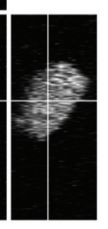

Fig. 2. Volume of the myocytes. A) Schematic of the rendering process. The border of the myocyte is detected for every slice in the 3D stack using the active contour algorithm. The volume is then calculated as the area inside the contour multiplied by the optical slice thickness and summed across all slices. B) Rendered volume for the diabetic and control myocytes (left panel), middle panel - volume calculated from myocyte dimensions where the approximation of the myocyte shape as an elliptic cylinder was used. The ratio between the rendered volume and the cylindrical approximation is shown on the lower right. Data are presented as minimum - first quartile median - third quartile - maximum and the
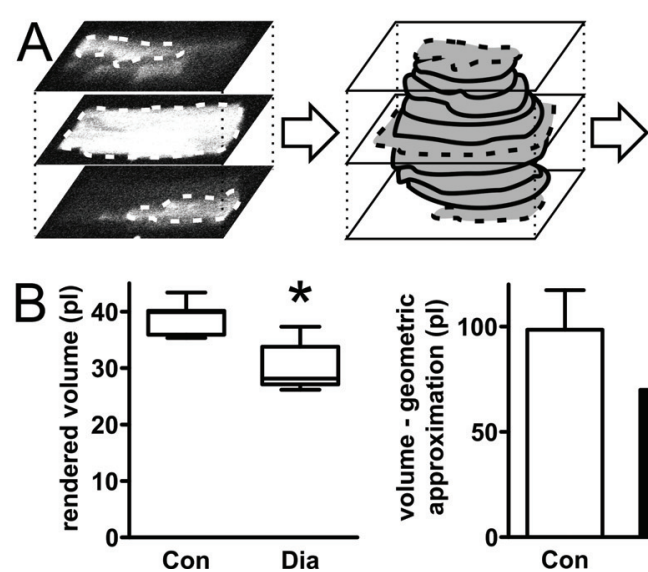
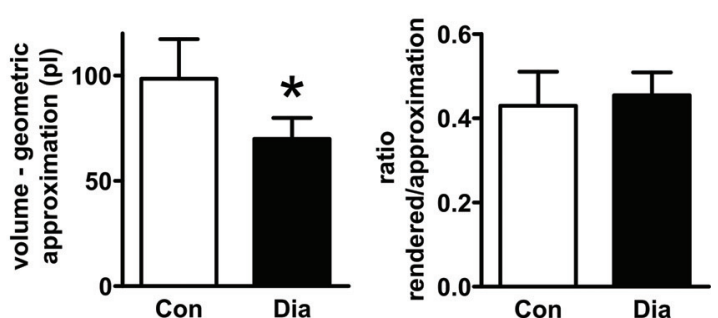
mean $\pm S D$, respectively. 
Myocyte volume data obtained by rendering the myocyte shape from the 3D confocal scans were first tested for normality using the Shapiro-Wilk's test because these data are often naturally skewed. Because this test rejected the null hypothesis of an expected normal distribution of volumes, we used a non-parametric test to examine between-group differences. We found a significant decrease $(\mathrm{p}=0.0002)$ in the rendered volume of diabetic myocytes (median $28.1 \mathrm{pl}, \mathrm{IQR} 6.7 \mathrm{pl}, \mathrm{N}=75$ cells analyzed) compared with the control group: median $39.9 \mathrm{pl}$, IQR $4.2 \mathrm{pl}, \mathrm{N}=70$ (Fig. $2 \mathrm{~B}, 95 \% \mathrm{CLs}$ for the difference between medians were 6.19 and 13.97).

To compare the rendered volume with a widely used geometric approximation of the myocyte as an elliptical cylinder $\left(\mathrm{V}_{\mathrm{e}}\right)$, we calculated volumes from the respective length, width and thickness data. Because both sets of calculated data had acceptable skewness values for normally distributed data, we described the data using the mean and SD. The estimated mean $\mathrm{V}_{\mathrm{e}}$ for the diabetic group was $70.0 \pm 10.0 \mathrm{pl}(\mathrm{N}=75$ cells analyzed) and was significantly lower than that found for the controls: $98.5 \pm 18.8 \mathrm{pl}, \quad \mathrm{N}=70 \quad(\mathrm{p}<0.001, \quad 95 \% \quad \mathrm{CLs}$ for the difference between means were 13.6 and 43.4). To assess possible bias in the volumes determined, which could be attributed to the main effect, i.e., the presence of the disease, we calculated the ratio of the rendered volume and the calculated approximate volume for the cells in both groups. The average ratio in the diabetic group was $0.45 \pm 0.05(\mathrm{~N}=75)$ and the ratio in the controls was $0.43 \pm 0.08(\mathrm{~N}=70)$. There was no significant difference in the ratio of rendered volume/geometric-approximation volume between the experimental and control groups; $95 \%$ CLs were -0.09 and 0.04 (Fig. 2B).

\section{Left ventricular myocyte calcium transients and shortening}

The calcium transients and cell shortening were acquired at $0.5 \mathrm{~Hz}$ and subsequently at $2 \mathrm{~Hz}$, therefore it was possible to correlate both variables (calcium transient amplitude (CTA) and relative shortening). The results of the CTA were analyzed using a fully nested ANOVA, which respects a hierarchical experimental design. The nested design allowed us to test: 1) the difference between experimental (diabetic) and control groups and 2) the variability of the animals within each group (interindividual variability). Residual variability depicted all other effects influencing intra-individual variability (cell to cell fluctuations).
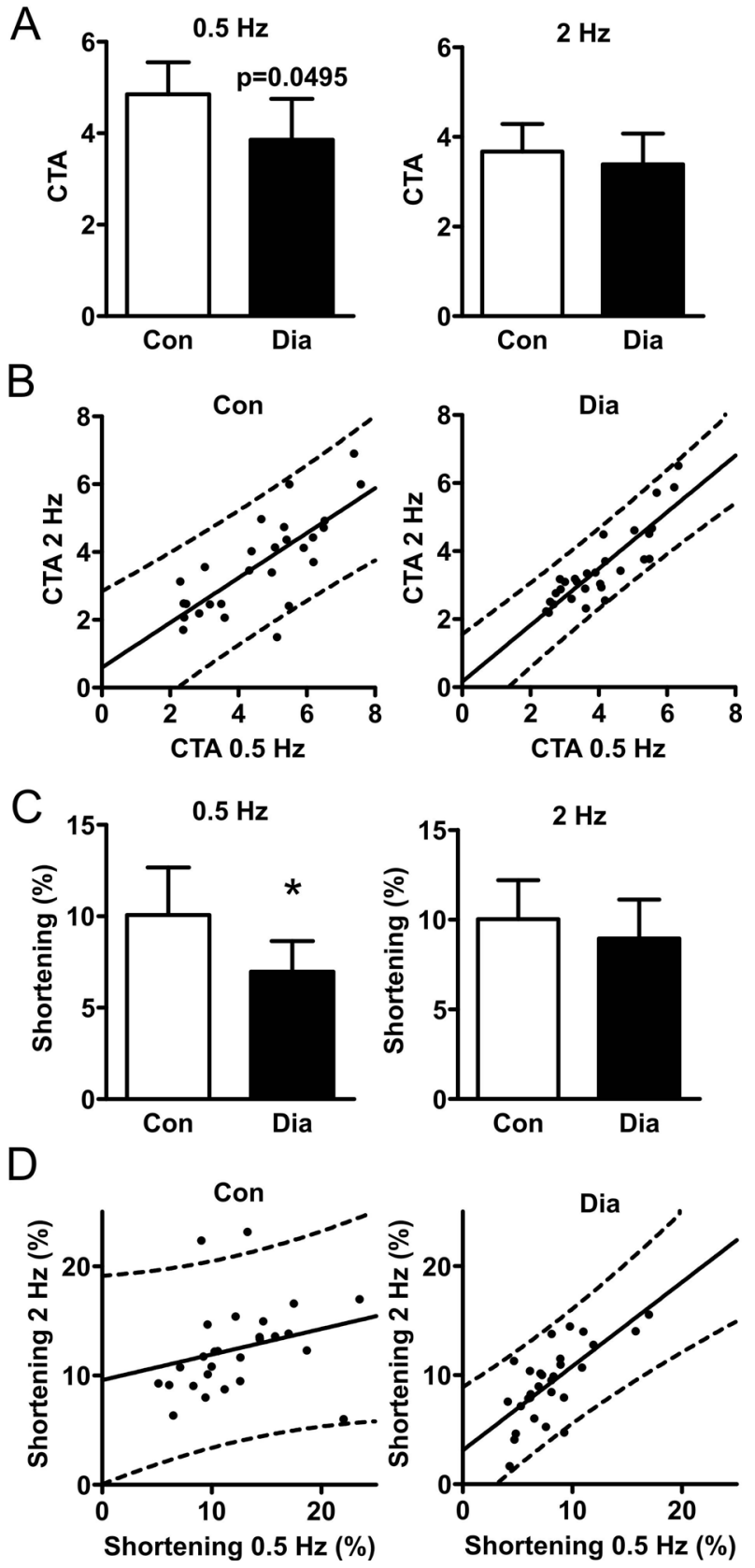

Fig. 3. The calcium transient amplitude (CTA) in the control and diabetic groups at stimulation frequencies of 0.5 and $2 \mathrm{~Hz}(\mathbf{A})$. B) The scatterplots of the CTA at 0.5 and $2 \mathrm{~Hz}$ in the control (left) and diabetic (right) groups. C) Cell shortening in the control and diabetic groups at 0.5 and $2 \mathrm{~Hz}$. D) The scatterplots of the cell shortening at 0.5 and $2 \mathrm{~Hz}$ in the control (left) and diabetic (right) groups. In B and D the $95 \%$ prediction interval was estimated using a simple linear regression analysis.

For CTA at $0.5 \mathrm{~Hz}$, we observed a significant difference between diabetic (mean value $4.03 \pm 1.18$ for $\mathrm{N}=29$ cells analyzed) and control myocytes (mean value $4.78 \pm 1.62, \mathrm{~N}=27)$. The test yielded a probability value of 0.0495 ( $95 \%$ CLs for the difference between means were -1.499 and -0.002 ), which demonstrated a significant decrease in CTA in the diabetic group (Fig. 3A). Intra- 
individual (residual) variability was relatively high, indicating heterogeneity between the cells isolated from the hearts of the animals in each group. Nevertheless, it did not abolish the effect between the groups.

For CTA at $2 \mathrm{~Hz}$, we did not observe any significant difference between the diabetic and control groups. The mean value of CTA for the diabetic group was $3.50 \pm 1.12(\mathrm{~N}=29)$ and for the control group, it was $3.64 \pm 1.42(\mathrm{~N}=27$; Fig. $3 \mathrm{~A})$.

Association between CTA values measured at both frequencies in the control group was analyzed using a bivariate correlation analysis. The calculated $r$ for this group was 0.76 and was significantly different from zero, which supports the assumption of a fairly strong linear relationship. However, we cannot reliably predict the CTA value at other than the experimentally used frequency of stimulation because $95 \%$ CI for the ' $r$ ' was quite wide and ranged from 0.531 to 0.883 .

Association between CTA values measured at both frequencies in the diabetic group: the correlation coefficient of $\mathrm{r}=0.869$ was significantly different from zero, confirming a linear relationship between the CTA recorded at the lower and higher frequencies. The relationship was robust, as indicated by the lower and upper boundaries of the $95 \% \mathrm{CI}(0.738$ and 0.937$)$. The scatterplots for both linear relationships, in the control and diabetic groups, are shown in Figure 3B.

After confirming the association between CTA values at each frequency, using t-tests, we tested the extent to which these different stimulation frequencies influenced the mean CTA values. For diabetic myocytes, we observed a significant decrease $(p<0.0001)$ in CTA measured at $2 \mathrm{~Hz}$ compared with the values measured at $0.5 \mathrm{~Hz}$ (mean difference was $-0.522 ; 95 \%$ CLs were 0.398 and 0.747 ). The decrease was also observed in the control group; the mean difference in CTA between stimulation frequencies - 0.972 (95\% CLs were 0.547 and 1.398) - was highly significant $(\mathrm{p}<0.0001)$. Testing of differences (CTA at $2 \mathrm{~Hz}-\mathrm{CTA}$ at $0.5 \mathrm{~Hz}$ ) between the control and diabetic groups showed a borderline significance $(\mathrm{p}=0.06)$.

Cell shortening at $0.5 \mathrm{~Hz}$. The data for cell shortening were analyzed as for CTA using ANOVA in a hierarchical arrangement. We observed a significant difference in cell shortening between the experimental groups: the mean value in the diabetic group $(7.2 \pm 1.7 \%$, $\mathrm{N}=82$ ) was significantly lower than that of the control group as shown in Figure $3 \mathrm{C}(9.6 \pm 2.6 \%, \mathrm{~N}=70$; $\mathrm{p}=0.008$ ). The analysis revealed a significant inter- individual (animals) variability $(\mathrm{p}=0.002)$. The relatively high residual variability also suggests a cell-to-cell heterogeneity within animals.

Cell shortening at $2 \mathrm{~Hz}$. ANOVA in a hierarchical arrangement did not confirm a significant difference between diabetic (mean value $8.7 \pm 2.2 \%$, $\mathrm{N}=82)$ and control $(9.7 \pm 2.2 \%, \mathrm{~N}=70)$ groups, although there was a trend for a decrease in cell shortening in the diabetic group (Fig. 3C). The data obtained for cell shortening showed lower inter-individual variability $(p=0.063)$ as it was observed at $0.5 \mathrm{~Hz}$ but residual (between cells) variability contributed significantly to the total variability.

Association between cell-shortening values measured at both frequencies in the control group. The correlation coefficient was calculated for 25 cells using paired measurements (two cells were confirmed as outliers and they were not included in the correlation analysis). The value of $\mathrm{r}$ was 0.741 and was highly significant $(\mathrm{p}<0.0001) .95 \% \mathrm{CLs}$ for ' $\mathrm{r}$ ' were 0.481 and 0.881 .

Association between cell shortening values measured at both frequencies in the diabetic group. The correlation coefficient was $0.697 \quad$ (29 paired measurements with no outliers) and was significantly different from zero $(\mathrm{p}<0.0001) .95 \%$ CLs for ' $\mathrm{r}$ ' were 0.445 and 0.847 . Scatterplots for the control and diabetic groups are presented in Figure 3D.

Relationship between the CTA and cell shortening. Simultaneous acquisition of the CTA and cell-shortening data in the same cell allowed us to determine the impact of the calcium transient amplitude on myocyte shortening. We analyzed this relationship separately in both groups of animals, at both stimulation frequencies. ANOVA results indicate that the variabilities between cells and between animals are quite comparable. Based on this ANOVA, the data were pooled across animals instead of taking mean values for the animals, which would yield incorrectly high correlations due to the removal of variation within animals.

The correlation coefficients for the control group were: $\mathrm{r}=0.209$ (95\% CLs: -0.212 to $0.565 ; \mathrm{N}=25$; $\mathrm{p}=0.327)$ for the $0.5 \mathrm{~Hz}$ stimulation frequency and $\mathrm{r}=0.206$ (95\% CLs: -0.215 to $0.563 ; \mathrm{N}=25 ; \mathrm{p}=0.334$ ) for the $2 \mathrm{~Hz}$ stimulation frequency. For the diabetic group, we obtained $r$ values of 0.336 (95\% CLs: -0.035 and $0.625 ; \mathrm{N}=29 ; \mathrm{p}=0.075)$ and 0.169 (95\% CLs: -0.210 and 0.504 ; $\mathrm{N}=29 ; \mathrm{p}=0.38$ ) for $0.5 \mathrm{~Hz}$ and $2 \mathrm{~Hz}$, respectively (Fig. 4C,D). 
A

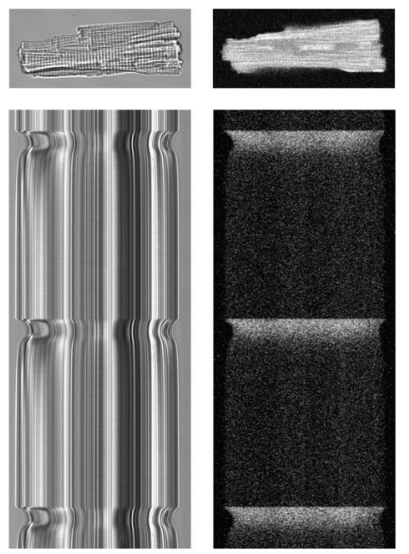

$B$

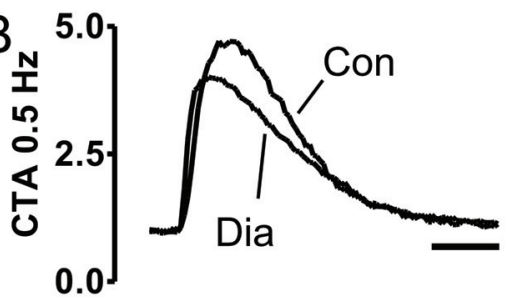

C Control

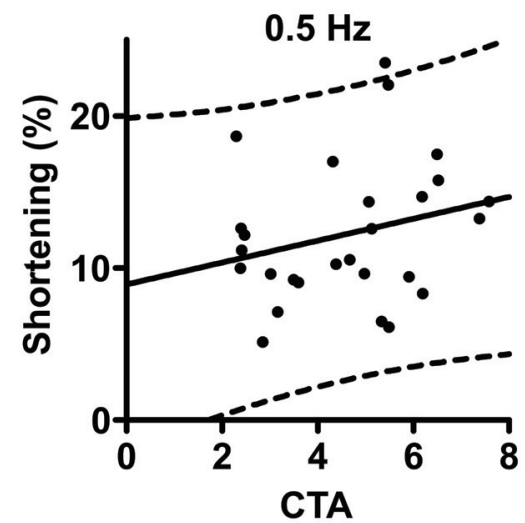

D Diabetes

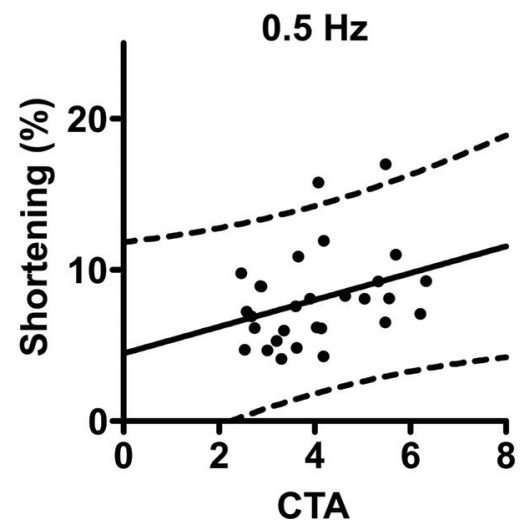

\section{Discussion}

This study was specifically focused to determine the size, volumes, shortening and calcium transients in left ventricular myocytes isolated one week after the
Fig. 4. Relationship between the calcium transient amplitude and the myocyte shortening with $95 \%$ prediction intervals. A) Representative image and linescans in brightfield and Fluo-3 fluorescence at 0.5 and $2 \mathrm{~Hz}$ stimulation frequencies. Linescans were taken quasi-simultaneously to correlate CTA and cell shortening. Horizontal bar: $10 \mu \mathrm{m}$, vertical bar: $0.5 \mathrm{~s}$. B) Traces of CTA as a function of time at stimulation frequency 0.5 and $2 \mathrm{~Hz}$, bar: $100 \mathrm{~ms}$. C, D) CTA and cell-shortening paired data were tested in the control (C) and diabetic (D) groups at each stimulation frequency.
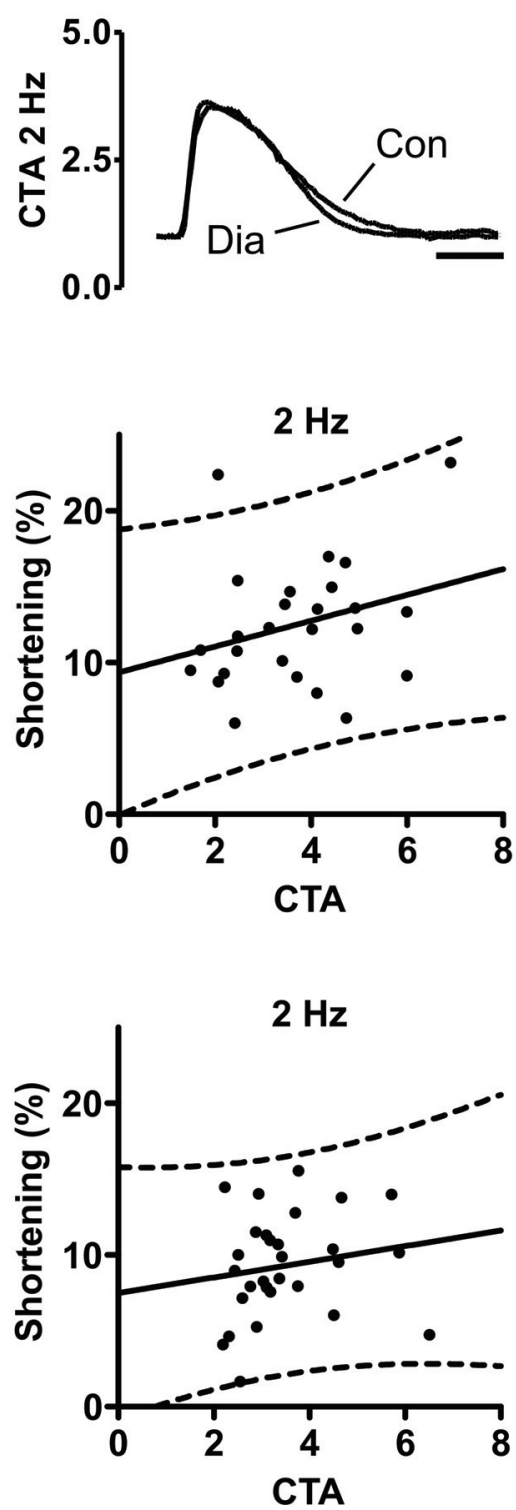

induction of diabetes in rats using a single dose of streptozotocin to better describe/resolve subtle changes in myocyte morphology and contractility in the early stages of diabetes. Diabetes in the STZ-treated rats was confirmed at just $24 \mathrm{~h}$ due to a four-fold elevation in 
blood glucose concentration, which remained stable until the day of the experiment (day seven). The $16 \%$ reduction in body weight in the diabetic group at one week after the STZ injection is consistent with previous studies performed in rats, which showed weight loss ranging from $11 \%$ to $27 \%$ (Malhotra et al. 1981, Ren et al. 1998, Delucchi et al. 2012). The reduction in body weight is indicative of lipolysis of adipose tissue, where free fatty acids (FFA) are released into the circulation. In the liver, they can be converted to triacylglycerols or lipoproteins containing cholesterol. However, under our experimental conditions, the triacylglycerols were not increased significantly and the cholesterol level showed borderline probability value. As we found minimal changes in both parameters, we can assume that the balance between the release and uptake of triacylglycerols and cholesterol remains consistent although the turnover is higher, which resulted in a significant reduction in body weight in the diabetic animals at just one week. An increase in creatinine in the blood is normally indicative of kidney malfunction; however, the clearance of creatinine should be analysed to clarify this point. The drop in body weight at day seven together with the stable increase in blood glucose concentration in the experimental animals is typical of established diabetes with an overstimulation of the catabolic machinery and is consistent with our previous experience and earlier studies (Ulicna et al. 1996, Bortolon et al. 2012).

The weight of the diabetic heart in rats is reduced in STZ-based models after two to twelve weeks (Bracken et al. 2004, Dyntar et al. 2006, Howarth and Qureshi 2006). As demonstrated by recent (Delucchi et al. 2012) and earlier studies (Malhotra et al. 1981, Ren et al. 1998), at one week after an injection of STZ, the heart weight is already reduced. To address the question of how the reduction in heart mass correlates with myocytes, the volumes and metric parameters were measured (Fig. 1A). We observed $\sim 30 \%$ decrease in the rendered myocyte volume. When comparing data provided by elliptical approximation of myocyte volume, our results are similar to the data published by Stilli et al. (2007) who used the elliptical approximation based on histological sections and showed a trend towards a reduction in myocyte volume after three weeks of diabetes. In contrast, after two weeks of STZ-induced diabetes, Dyntar et al. (2006) described no change in myocyte volume, again based on histomorphometrical analysis. Because histomorphometrical analyses generate variable results, accepting actual myocyte shape for the accurate estimation of myocyte volume, especially in the early stages of the disease, may circumvent this issue. When comparing the heart weight and the myocyte volume, the almost $30 \%$ decrease in the rendered myocyte volume observed in this study is comparable with a decrease in heart weight of $\sim 25 \%$ after 14 days (Dyntar et al. 2006, Stilli et al. 2007). In studies performed at one week after administration of STZ in rats, the published reduction in heart weight is $21 \%$ and $16 \%$ respectively (Malhotra et al. 1981, Ren et al. 1998). One reason underlying the greater drop in the volume of a single myocyte compared with the loss in heart weight could be a promotion of myocyte cytokinesis. Indeed, in diabetic rats, Stilli et al. (2007) observed higher DNA replication and increased mitotic activity of cardiac myocytes, which was concluded to be due to the generation of new cardiomyocytes. Therefore, an increase in myocyte mitosis, followed by myocyte cytokinesis, could result in a higher number of smaller myocytes. This should be then reflected by a shift in distribution curves of metric parameters towards smaller values in diabetic group, especially those for the lengths and volumes. However, in this study we have not found any significant changes in distribution curves of metric parameters. Thus, we can conclude that in our experimental conditions, the loss in myocyte volume resulted probably from myocyte shrinkage, however, a presence of hyperplastic responses which could underlie the loss of ventricular mass could also take place. Taken together, the mechanism of left ventricular mass reduction in diabetes appears complex and other parameters, such as collagen content, myocyte apoptosis and myocyte mitotic divisions, need to be taken into consideration also.

We identified the width and length as the dominant factors contributing to the decrease in myocyte volume, with the width being more prominent because it decreased to $85 \%$ of its original value compared with length, which was reduced by $11 \%$, the latter perfectly matching with a previous study at day six after STZ injection in rats (Ren et al. 1999). Thus, the reduction in myocyte mass did not result from proportional changes in all three metric parameters, and a preferred reduction in the xy-direction was observed. Asymmetric rearrangement of diabetic mycoytes appears to be caused by several mechanical, neurohumoral and electrochemical factors. Shrinkage predominantly in the xy-axes could arise from specific anatomical changes of the diabetic left ventricle (Stilli et al. 2007). Additionally, 
asymmetric myocyte reorganisation could be an adaptive response to increased myocyte apoptosis, which has been shown to be maximal at the third day after STZ injection (Fiordaliso et al. 2000). Moreover, expression of connexin43, the main ventricular connexin isoform, was decreased in diabetic rat hearts concomitant with a loss of contacts between cardiomyocytes (Dyntar et al. 2006). All these can potentiate myocyte spatial reorganization to compensate for the alteration in mechanical contacts and electrical conductivity between neighbouring cells. However, a more focused study of the anatomy and structure of the left ventricle is required to determine which of these processes specifically causes the observed myocyte asymmetrical reduction in volume at this stage of diabetes.

We observed a clear difference between the rendered myocyte volume $\left(\mathrm{V}_{\mathrm{r}}\right)$ and the volume calculated by the standard approximation of the myocyte shape as an elliptic cylinder $\left(\mathrm{V}_{\mathrm{e}}\right)$. The $\mathrm{V}_{\mathrm{r}}$ of the myocytes was, on average, $43 \%$ that of the $V_{e}$, i.e. less than half, which is comparable with the correction factor used by Satoh et al. (1996) in a study performed to analyze myocyte volume precisely. Authors McCrossan et al. (2004) provide similar results when using a $54 \%$ correction factor for calculating $\mathrm{V}_{\mathrm{r}}$ from $\mathrm{V}_{\mathrm{e}}$. Therefore, taking the actual shape of myocytes into account is of critical importance for the accurate estimation of volume, especially when absolute values of myocyte volumes are intended to be compared with tissue or whole-organ results.

Together with the morphological derangements, myocyte function also appeared to be also negatively altered during the acute phase of diabetes - we found a significant decrease in myocyte shortening in the diabetic group at a stimulation frequency of $0.5 \mathrm{~Hz}$. Several authors have found depressed contractility in diabetic myocytes in the $8^{\text {th }}-12^{\text {th }}$ week of diabetes (Ding et al. 2006, Wickley et al. 2006). However, other authors have found no difference (Rithalia et al. 2004) in the same period. When focused closer to the early stages of STZinduced diabetes, for example at six days after STZ injection, Ren et al. (1999) observed no change in myocyte shortening when stimulated at $0.5 \mathrm{~Hz}$. A recent study also showed that cell shortening at $1 \mathrm{~Hz}$ was unaltered (Delucchi et al. 2012) at one week after induction of diabetes. Therefore, we paced myocytes at a basic frequency of $0.5 \mathrm{~Hz}$ followed by stimulating at $2 \mathrm{~Hz}$, the latter of which is a frequency closer to the physiological rate in rats. A novel result of our study is the decrease in cell shortening, where the stimulation frequency of $0.5 \mathrm{~Hz}$ appears more optimal because it better discriminates the diabetic group than the stimulation frequency of $2 \mathrm{~Hz}$. Moreover, the results point to the fact that the stimulation frequency used for myocyte stimulation must be selected with care and may explain discrepancies observed in studies of myocyte shortening.

Because the decrease in cell shortening could originate from a decrease in the peak systolic $\mathrm{Ca}^{2+}$ concentration $\left(\mathrm{Ca}^{2+}\right.$ transient) or from the change in the myofilament $\mathrm{Ca}^{2+}$ sensitivity, we recorded the CTA simultaneously with the shortening and analyzed the CTA-shortening relationship. As we found a significant decrease in the CTA at $0.5 \mathrm{~Hz}(\mathrm{p}=0.04)$, we suggest that the decreased calcium transient is one of the factors contributing to the decreased shortening in the diabetic group although after one week of STZ-induced diabetes in rats, published studies have shown a minimal change in $\mathrm{Ca}^{2+}$ transients at 0.5 and $1 \mathrm{~Hz}$ stimulation frequencies (Delucchi et al. 2012, Ren et al. 1999). However, several authors have confirmed a decreased peak calcium transient in diabetic rats at four to twelve weeks after inducing diabetes (Noda et al. 1993, Lagadic-Gossmann et al. 1996, Ding et al. 2006, Wickley et al. 2006). We attempted to determine whether $\mathrm{Ca}$ sensitivity is an additional factor responsible for the decrease in shortening by comparing the CTA-shortening curves; however, the correlation between CTA and shortening was poor due to high cell-to-cell variability (Fig. 4C,D). Descriptions of alterations in $\mathrm{Ca}^{2+}$ sensitivity in the literature are inconsistent: hearts from diabetic animals have been shown to have decreased sensitivity to external $\mathrm{Ca}^{2+}$ (Bielefeld et al. 1983). In contrast, an increase in $\mathrm{Ca}^{2+}$ sensitivity was observed in skinned cardiac fibres (Murat et al. 1989, Khandoudi et al. 1993). Therefore, we suggest that impaired calcium handling is one of the factors responsible for the observed decrease in myocyte shortening. However, the contribution of several other factors, such as expression of enzymes contributing to $\mathrm{Ca}^{2+}$ homeostasis, a shift in expression of sarcomeric proteins, enhanced oxidative stress or compromised respiratory chain function (Waczulikova et al. 2007, Ziegelhoffer et al. 2009) cannot be excluded and will be addressed in future experiments.

A statistical analysis of our data revealed heterogeneity in the myocyte volumes together with CTA and shortening in the control group that was significantly higher when compared with the diabetic group. To highlight this idea, we performed correlation analysis of 
the CTA at $0.5 \mathrm{~Hz} v s .2 \mathrm{~Hz}$ as well as correlation of the shortening at $0.5 \mathrm{~Hz}$ vs. $2 \mathrm{~Hz}$ (Fig. 3B,D) in the control and the diabetic group. In all cases we found significantly lower $95 \%$ CI in the diabetic group compared to control group. Similar trend was found when we compared the CTA-shortening relationship (Fig. 4C,D). We could interpret this result as a simplification of system behaviour during pathology, i.e. a loss in complexity and therefore a more simple reaction to adverse stimuli. A system that has limited responses has reduced ability to protect itself with, non-standard' reactions to detrimental stimuli. Therefore it is more prone to a defective functioning and to an earlier onset of destructive processes.

To reveal and reliably discriminate subtle differences between experimental and control groups, animals and cells, the use of advanced statistical methods is essential. To analyse the effects between groups and between subgroups within the groups, we used fully nested ANOVAs followed by a multiple comparison procedure to reveal specific differences between pairs of the groups. CTA and cell shortening results show that, unlike the individual animals, the control and diabetic groups do contribute to the overall variability when recording at $0.5 \mathrm{~Hz}$. However, cells from each individual animal, as indicated by the residual sum of squares, contribute more to the total variability. This fact could mask true disease effects, which could be addressed by increasing the number of cells investigated per animal.

In conclusion, we used an automated segmentation method based on an active contour algorithm to determine the volumes of single myocytes during the acute phase of streptozotocin-induced diabetes in rats. We showed a reduction in myocyte volume in the diabetic group. The alterations in the metric parameters were not proportionally related, which may indicate a structural reorganization of the heart tissue. Additionally, as revealed by advanced statistical methods, the myocyte shortening and calcium homeostasis were also negatively affected.

\section{Conflict of Interest}

There is no conflict of interest.

\section{Acknowledgements}

We thank Dr. Anton Mateasik, PhD. for his helpful suggestions regarding the active contour algorithm and for computer programming. Special thank to Dr. Miriam Ann Hickey, PhD. for careful proofreading and for language corrections. The original experimental data presented were obtained with the support of research grants 2/0094/12 from VEGA and UK/399/2007 from Comenius University, Bratislava, Slovakia. Data analysis was facilitated by the grant KEGA 003UK-4/2012.

\section{References}

BERTONI AG, TSAI A, KASPER EK, BRANCATI FL: Diabetes and idiopathic cardiomyopathy - A nationwide casecontrol study. Diabetes Care 26: 2791-2795, 2003.

BIELEFELD DR, PACE CS, BOSHELL BR: Altered sensitivity of chronic diabetic rat heart to calcium. Am J Physiol 245: E560-E567, 1983.

BORTOLON JR, SILVA AJ JR, MURATA GM, NEWSHOLME P, CURI R, PITHON-CURI TC, HATANAKA E: Persistence of inflammatory response to intense exercise in diabetic rats. Exp Diabetes Res 2012: Article ID 213986, 2012.

BRACKEN NK, WOODALL AJ, HOWARTH FC, SINGH J: Voltage-dependence of contraction in streptozotocininduced diabetic myocytes. Mol Cell Biochem 261: 235-243, 2004.

CHATTOU S, DIACONO J, FEUVRAY D: Decrease in sodium-calcium exchange and calcium currents in diabetic rat ventricular myocytes. Acta Physiol Scand 166: 137-144, 1999.

CHORVATOVA A, CAGALINEC M, MATEASIK A, CHORVAT D JR: Estimation of single cell volume from 3D confocal images using automatic data processing. SPIE Biophotonics 8427: 1-10, 2012.

DANAEI G, FINUCANE MM, LIN JK, SINGH GM, PACIOREK CJ, COWAN MJ, FARZADFAR F, STEVENS GA, LIM SS, RILEY LM, EZZATI M: National, regional, and global trends in systolic blood pressure since 1980: systematic analysis of health examination surveys and epidemiological studies with 786 country-years and 5.4 million participants. Lancet 377: 568-577, 2011. 
DELUCCHI F, BERNI R, FRATI C, CAVALLI S, GRAIANI G, SALA R, CHAPONNIER C, GABBIANI G, CALANI L, DEL RIO D, BOCCHI L, LAGRASTA C, QUAINI F, STILLI D: Resveratrol treatment reduces cardiac progenitor cell dysfunction and prevents morpho-functional ventricular remodeling in type-1 diabetic rats. PloS One 7: e39836, 2012.

DING Y, ZOU R, JUDD RL, ZHONG J: Effects of gender difference on cardiac myocyte dysfunction in streptozotocin-induced diabetic rats. Endocrine 29: 135-141, 2006.

DYNTAR D, SERGEEV P, KLISIC J, AMBUHL P, SCHAUB MC, DONATH MY: High glucose alters cardiomyocyte contacts and inhibits myofibrillar formation. J Clin Endocrinol Metab 91: 1961-1967, 2006.

FIORDALISO F, LI BS, LATINI R, SONNENBLICK EH, ANVERSA P, LERI A, KAJSTURA J: Myocyte death in streptozotocin-induced diabetes in rats is angiotensin II-dependent. Lab Invest 80: 513-527, 2000.

FIORDALISO F, CUCCOVILLO I, BIANCHI R, BAI A, DONI M, SALIO M, DE ANGELIS N, GHEZZI P, LATINI R, MASSON S: Cardiovascular oxidative stress is reduced by an ACE inhibitor in a rat model of streptozotocin-induced diabetes. Life Sci 79: 121-129, 2006.

GIACOMELLI F, WIENER J: Primary myocardial disease in the diabetic mouse. An ultrastructural study. Lab Invest 40: 460-473, 1979.

HOWARTH FC, QURESHI MA, WHITE E: Effects of hyperosmotic shrinking on ventricular myocyte shortening and intracellular Ca2+ in streptozotocin-induced diabetic rats. Pflugers Arch 444: 446-451, 2002.

HOWARTH FC, QURESHI MA: Effects of carbenoxolone on heart rhythm, contractility and intracellular calcium in streptozotocin-induced diabetic rat. Mol Cell Biochem 289: 21-29, 2006.

KASS M, WITKIN A, TERZOPOULOS D: Snakes - active contour models. Int J Comput Vis 1: 321-331, 1987.

KHANDOUDI N, GUO AC, CHESNAIS M, FEUVRAY D: Skinned cardiac fibres of diabetic rats: contractile activation and effects of 2,3-butanedione monoxime (BDM) and caffeine. Cardiovasc Res 27: 447-452, 1993.

KITA Y, SHIMIZU M, SUGIHARA N, SHIMIZU K, YOSHIO H, SHIBAYAMA S, TAKEDA R: Correlation between histopathological changes and mechanical dysfunction in diabetic rat hearts. Diabetes Res Clin Pract 11: 177-188, 1991.

LAGADIC-GOSSMANN D, BUCKLER KJ, LE PK, FEUVRAY D: Altered Ca2+ handling in ventricular myocytes isolated from diabetic rats. Am J Physiol 270: H1529-H1537, 1996.

MALHOTRA A, PENPARGKUL S, FEIN FS, SONNENBLICK EH, SCHEUER J: The effect of streptozotocininduced diabetes in rats on cardiac contractile proteins. Circ Res 49: 1243-1250, 1981.

MALHOTRA A, SANGHI V: Regulation of contractile proteins in diabetic heart. Cardiovasc Res 34: 34-40, 1997.

MCCROSSAN ZA, BILLETER R, WHITE E: Transmural changes in size, contractile and electrical properties of SHR left ventricular myocytes during compensated hypertrophy. Cardiovasc Res 63: 283-292, 2004.

MURAT I, VEKSLER VI, VENTURA-CLAPIER R: Effects of halothane on contractile properties of skinned fibers from cardiomyopathic animals. J Mol Cell Cardiol 21: 1293-1304, 1989.

NEMOTO O, KAWAGUCHI M, YAOITA H, MIYAKE K, MAEHARA K, MARUYAMA Y: Left ventricular dysfunction and remodeling in streptozotocin-induced diabetic rats. Circ J 70: 327-334, 2006.

NODA N, HAYASHI H, SATOH H, TERADA H, HIRANO M, KOBAYASHI A, YAMAZAKI N: Ca2+ transients and cell shortening in diabetic rat ventricular myocytes. Jpn Circ J 57: 449-457, 1993.

REN J, WALSH MF, HAMATY M, SOWERS JR, BROWN RA: Altered inotropic response to IGF-I in diabetic rat heart: influence of intracellular Ca2+ and NO. Am J Physiol 275: H823-H830, 1998.

REN J, WALSH MF, HAMATY M, SOWERS JR, BROWN RA: Augmentation of the inotropic response to insulin in diabetic rat hearts. Life Sci 65: 369-380, 1999.

RITHALIA A, QURESHI MA, HOWARTH FC, HARRISON SM: Effects of halothane on contraction and intracellular calcium in ventricular myocytes from streptozotocin-induced diabetic rats. Br J Anaesth 92: 246-253, 2004.

SATOH H, DELBRIDGE LM, BLATTER LA, BERS DM: Surface:volume relationship in cardiac myocytes studied with confocal microscopy and membrane capacitance measurements: species-dependence and developmental effects. Biophys J 70: 1494-1504, 1996. 
STILLI D, LAGRASTA C, BERNI R, BOCCHI L, SAVI M, DELUCCHI F, GRAIANI G, MONICA M, MAESTRI R, BARUFFI S, ROSSI S, MACCHI E, MUSSO E, QUAINI F: Preservation of ventricular performance at early stages of diabetic cardiomyopathy involves changes in myocyte size, number and intercellular coupling. Basic Res Cardiol 102: 488-499, 2007.

ULICNA O, VOLKOVOVA K, ISTVANOVA B: Bioenergetics of liver mitochondria in rats in experimental insulindependent diabetes (in Slovak). Bratisl Lek Listy 97: 619-624, 1996.

WACZULIKOVA I, HABODASZOVA D, CAGALINEC M, FERKO M, ULICNA O, MATEASIK A, SIKUROVA L, ZIEGELHOFFER A: Mitochondrial membrane fluidity, potential, and calcium transients in the myocardium from acute diabetic rats. Can J Physiol Pharmacol 85: 372-381, 2007.

WANG DW, KIYOSUE T, SHIGEMATSU S, ARITA M: Abnormalities of $\mathrm{K}+$ and Ca2+ currents in ventricular myocytes from rats with chronic diabetes. Am J Physiol 269: H1288-H1296, 1995.

WICKLEY PJ, SHIGA T, MURRAY PA, DAMRON DS: Propofol decreases myofilament Ca2+ sensitivity via a protein kinase C-, nitric oxide synthase-dependent pathway in diabetic cardiomyocytes. Anesthesiology 104: 978-987, 2006.

ZAHRADNIK I, PALADE P: Multiple effects of caffeine on calcium current in rat ventricular myocytes. Pflugers Arch 424: 129-136, 1993.

ZHANG XL, CHEN C: A new insight of mechanisms, diagnosis and treatment of diabetic cardiomyopathy. Endocrine 41: 398-409, 2012.

ZIEGELHOFFER A, WACZULIKOVA I, FERKO M, KINCELOVA D, ZIEGELHOFFER B, RAVINGEROVA T, CAGALINEC M, SCHONBURG M, ZIEGELHOEFFER T, SIKUROVA L, ULICNA O, MUJKOSOVA J: Calcium signaling-mediated endogenous protection of cell energetics in the acutely diabetic myocardium. Can J Physiol Pharmacol 87: 1083-1094, 2009. 